\title{
Research on Informatization Construction of Small and Medium Sized Logistics Enterprises in Binzhou City
}

\author{
Xue Gou \\ Business school, Binzhou Polytechnic, Binzhou 256603, China \\ gouxue001@126.com
}

Keywords: Binzhou, logistics enterprises, information construction.

\begin{abstract}
As of 2016 the city of Binzhou social science planning and key research project, through the investigation and analysis of Binzhou city informatization construction of small and medium-sized logistics enterprises, and put forward feasible suggestions to improve the level of Binzhou city social logistics information resources development and utilization, improve the level of government logistics services and supervision, improve the level of information on logistics industry and regional logistics, promoting the innovation and development of logistics information technology.
\end{abstract}

\section{Introduction}

The development of modern logistics is an effective way to adapt to the new situation of market economy, promote the virtuous circle of national economy and improve the quality and efficiency of economic operation.

Binzhou city in Shandong province is located in the center of the Yellow River Delta region, the goal is to build the important logistics nodes docking Tianjin Binhai New Area, serving Ji'nan city circle, linkage Bohai economic circle and peninsula city group implementation efforts.According to the requirements of Binzhou city"13th Five-Year" logistics development planning, to force the development of smart logistics, timely research to develop "Internet +" the action plan of goods and logistics, and further promote the mobile Internet, big data, cloud computing and other new generation of information technology application, at the same time, strengthen the construction of public logistics information platform, improve platform services. Informatization construction of small and medium-sized logistics enterprises can promote the implementation of the "13th Five-Year plan" to a great extent.

\section{Small and Medium-sized Logistics Enterprise Informatization Construction Situation in Binzhou City}

A sample survey of 20 small and medium-sized logistics enterprises in Binzhou was conducted about the investigation depth of information construction, found that small and medium-sized logistics enterprises in Binzhou city in the implementation of information technology mainly in the following points.

\subsection{Application of Advanced Logistics Technology is Not in Place}

Logistics standardization, generally from the use and effect of the standardization, seriation, standardization of transportation, warehousing, loading and unloading, packing facilities and bar code, information exchange, smart label technology to measure.

Through the investigation of 20 Binzhou city informatization construction of small and medium sized logistics enterprises that nearly $70 \%$ of the enterprises only stay on the basic information such as the "bar code", "GPS+GIS", "RF", and other advanced logistics information technologies, such as the "path optimization" and "inventory control technology" and "network technology", "electronic data interchange EDI technology "are not ideal. In the higher degree of information and automation equipment selection, only 30\% enterprise application “automatic warehouse”, “automatic conveyor”, 
"automatic sorting system", therefore, the application of the advanced logistics technology in small and medium sized logistics enterprises in Binzhou city is not in place.

\subsection{Construction of Information Public Platform is not Universal}

The importance of the public information platform is that it can let all participants to free access to information, social resources can be fully displayed and the use of performance, in market economy as the main body of knowledge (information resources) the urgent needs.

Learn from the results of the questionnaire, when asked" Which units are connected with the enterprise" ,only banks and tax units "get the full fare tickets", and customers, suppliers, information service institutions and the enterprise network rate of only 20\%, thus, the construction of Binzhou city logistics enterprises of small and medium sized public information platform is not universal.

\subsection{Lack of Professionals in Information Construction}

Professional talents are the core of enterprise and social development, and the platform of "developing enterprise exhibition platform and integrating enterprise resources". Modern logistics management concepts including scientific management, intelligent handling of cargo stowage, mechanical, electronic and other accounts, the application of these advanced concepts mainly relying on the professional information construction personnel.

In the survey shows that over more than half of the enterprises in the information construction process "concern about data security and trade secret theft" and "have no idea how to construct the enterprise informatization", in addition, the IT staff surveyed all controlled enterprises owned enterprises accounted for the proportion of employees in less tha $2 \%$.Some enteprises reflect that the enterprise's primary level operators are not able to adapt to the new information software and hardware, and the training is difficult,, and do not know how to build the company's information, it shows that the enterprise information construction seriously lack of professional talents.

\section{Binzhou Small and Medium-sized Logistics Enterprise Information Construction Status Analysis}

\subsection{Affected by Regional Natural Geographical Environment}

Transportation is one of the pillars of the logistics industry, Binzhou City is in the north of Shandong Province, northern Shandong Plain of the Yellow River Delta, , covers an area of 9600 square kilometers, is located in the efficient ecological economic zone of the Yellow River Delta, Shandong Peninsula Blue Economic Zone and the Bohai economic circle, Ji'nan provincial capital city economic circle "two zone and two circles" overlay zone, the northern gate of Shandong province. Logistics from the perspective of enterprise development, abundant land resources and labor resources, and between the city of Binzhou is located in the Beijing Tianjin Hebei and Jiaodong Peninsula, Weiwu expressway, Tianjin Shantou Expressway criss crossing Binzhou, formed into the national traffic artery pattern, having a good road transport prospects.

But the city temporarily no airport, railway lines fewer and single, and the input of Binzhou port is relatively late, so the city's air transport, railway transportation and waterway transport have been greatly restricted, the transportation of the advanced, modern information technology and equipment utilization rate is low, which effects the process of informationization of logistics enterprises.

\subsection{Affected by the Regional Industrial Development Structure}

In recent years, the agricultural development and industrial development in Binzhou have developed rapidly, with regional key industrial industries and large market demand, such as in agriculture, the Yellow River Delta National Agricultural Science and Technology Park, city National Agricultural Science and Technology Park, along the Huang Shengtai efficient modern agriculture demonstration zone to speed up construction, "Bohai granary" demonstration area to 250 thousand acres of development, in industry, Wei bridge group sales revenue reached 338 billion 500 million yuan, ranking the top 500 ranked 234Th in the world. Happy home textile won the national science and technology progress two prize. Actively resolve excess production capacity, steel, electrolytic aluminum production capacity included in the Ministry of industry in line with the industry standard conditions list. Affected by the regional industrial development structure of 
Binzhou, the traditional logistics function modules such as warehousing, distribution and so on have broad prospects for development.

But the current Binzhou city logistics enterprises have smaller scale, fewer high standard logistics park, scattered logistics management, logistics departments fragmentation phenomenon is more serious, high standard of logistics software acquisition and information platform construction are more difficult, logistics business functions and business scope of a single, which have become obstacles to promote enterprise information construction.

\subsection{Affected by Regional Political and Economic Conditions}

In recent years, Binzhou municipal government attaches great importance to the development of the logistics industry, according to the requirements of the "13th Five-Year" Binzhou city logistics development planning, we should vigorously develop the intelligent logistics, timely research to develop the "Internet +" action plan of goods and logistics, and further promote the mobile Internet, big data, cloud computing and other new generation of information technology application, at the same time, strengthen the construction of public logistics information platform, improve platform services.

At present, Binzhou's economic development level is relatively low, to a certain extent affected the Binzhou production capacity and consumption capacity, logistics enterprises will also receive the impact of the economic environment, the development of information construction will have certain difficulties. At the same time, the government in the construction of logistics enterprises information support policies, trainings, consultations, lectures, and professional information personnel introduction policy are not enough.

\section{Binzhou Small and Medium-sized Logistics Enterprise Informatization Construction Strategy}

\subsection{Promoting the Standardization of Information Construction and Evaluation Mechanism}

From the management point of view, the internal management system is unscientific, non-standard, non-standard, can lead to a large number of problems. Advanced management system can make each part of the work in an organization can, in accordance with established procedures in advance, and afterwards the whole process control, thus speeding up the construction of logistics standardization is particularly important.

With the popularization and application of international standards of logistics technology standards, the construction of the Binzhou city public logistics information platform, realize the sharing of information resources and logistics online tracking and process control, design evaluation model, establish the information evaluation system of logistics enterprise informationization construction, utilization of quantified, so that logistics enterprises transformed from traditional logistics to modern logistics informationization, and gradually formed a new pattern of logistics informationization.

\subsection{Stepping up Efforts to Train and Introduce Technical Personnel}

Excellent talents are the foundation of realizing enterprise strategic target and the motive force of enterprise sustainable development. Each profession, each domain, if does not have the specialized talented person's participation, can not obtain the good, the quicker development. The rapid development of the logistics industry also belongs to the high-tech industry, the high-tech talent shortage, the local government should intensify propaganda, as soon as possible to develop a high level logistics informatization and related professional and technical personnel training and the introduction of the policy, And strengthen the support for logistics informatization talents in the project application, the results of promotion, financing and so on , and effectively solve the introduction of talent in the employment, social security, household registration, education, housing and other aspects of the problemto provide enough high-quality professional talents for enterprise informatization construction. 


\subsection{Implementing Information Technology Support Policies}

For small and medium-sized logistics enterprises, the government needs to provide certain financial support, such as the public platform software should be installed free of charge, giving some grants for the purchase of personalized logistics information software and hardware equipment.

Pay attention to information technology training for logistics enterprises, government departments or additional information consulting agency, analysis of outstanding cases of other enterprises and solutions, to provide new technology application, data security processing and new service mode of the application of lectures, training and consulting work, accelerate the use of cyber source sharing and network security system as well as the implementation of enterprise informationization and popularization the application of the process.

\subsection{Attach importance to school enterprise cooperation and attach importance to the scientific research power of Universities}

The enterprise should be the local colleges and universities as the research base and talent incubator, promote the cooperation between colleges and universities should actively respond to the needs of the development of high-tech industry, setting the adjustment of higher professional courses, and founded the center or base for training of specialized personnel, to meet the urgent need of industry.

There are many universities such as Binzhou University, Binzhou Polytechnic in Binzhou City area, the development trend of professional electrical automation, logistics management is good, the universities should vigorously promote cooperation, especially should exert the advantage of scientific research, information technology in the construction of low cost, low attention development, difficulty of logistics software popularization and use, for example, combined with GSM technology, realize the logistics documents the information displayed, reduce business costs and promote the process of information.

\section{Summary}

Promoting the informatization construction of small and medium-sized logistics enterprises, logistics management, information flow through the support and regulation and leading logistics, improve the logistics management level, enhance logistics capability, logistics to improve the quality of growth, not only for the city of Binzhou, for the development of Shandong province and the logistics industry transformation and Industry are of great significance to establish. With the national modern logistics system and the coordinated development of logistics information system, lay the foundation for the development of logistics informationization.

\section{Acknowledgments}

This work was financially supported by "2016 the city of Binzhou social science planning and key research project "fund.

\section{References}

[1] Xia huosong. Logistics management information system [J]., higher education press, 2016, (08).

[2] Xiu Guihua, Wang Songchun. Logistics information system and application case [J]. Tsinghua University press, 2015, (01)

[3] Huang Fuhua, et al. Logistics management of modern enterprises [J]. Science Press, 2015, (07)

[4] Lu Yuduo. International press, [J]. logistics science 2014, (07). 